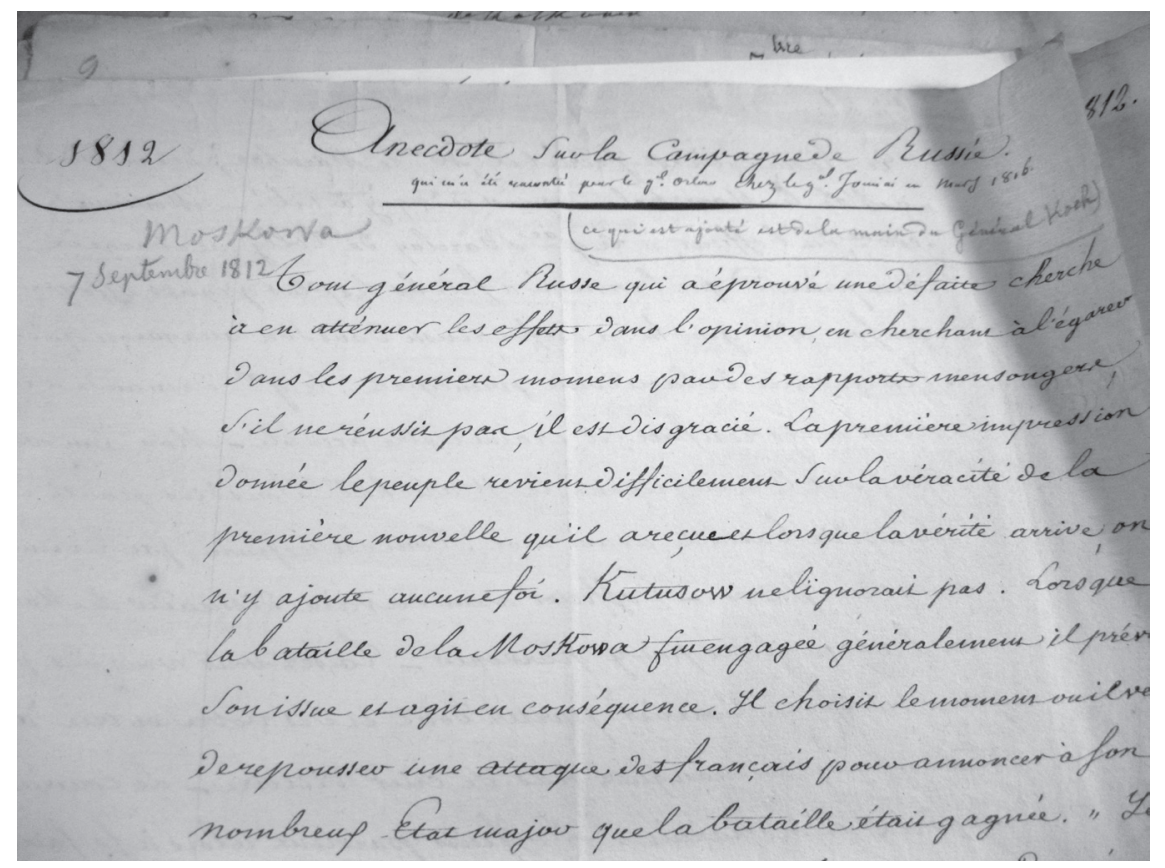

Неизвестный автор. Заметки «Anecdote sur la Campagne de Russie». 1816 (?). Париж, Service historique de la Défense. C2 130

\title{
Miscellanea
}


DOI 10.15826/qr.2015.2.107

УДК 94(470)“1812”+821.161.1 Толстой-31+82.091

Владимир Земцов

\author{
МИХАИЛ КУТУЗОВ, ЛЮДВИГ ФОН ВОЛЬЦОГЕН \\ И ЖАРЕНАЯ КУРИЦА (ЭПИЗОД БОРОДИНСКОГО \\ СРАЖЕНИЯ В ИСТОРИЧЕСКОМ ДОКУМЕНТЕ \\ И РОМАНЕ ЛЬВА ТОЛСТОГО)
}

\title{
Vladimir Zemtsov
}

\section{MIKHAIL KUTUZOV, LUDWIG VON WOLZOGEN \\ AND ROAST CHICKEN (AN EPISODE OF THE BATTLE \\ OF BORODINO IN AN HISTORICAL DOCUMENT AND LEO TOLSTOY'S NOVEL)}

L. N. Tolstoy's War and Peace describes the arrival of adjutant L. Wolzogen at M. I. Kutuzov's headquarters during the battle of Borodino in an attempt to convince the commander that the battle had been lost. Kutuzov rejects the message and states that the enemy has been defeated, claiming that the Russian army will embark on the offensive the following day. Tolstoy describes the events ironically, and the scene demonstrates different human and national attitudes to the war. Kutuzov is characterized by perspicacity and wisdom, a levelled attitude and belief in the Russian Army. Ludwig Wolzogen, an officer of German descent, is a man of pedantic calculation that does not believe in the possibility for the Russians to win the war. Besides the fact that this description determined the perception of the events in question by Tolstoy's readers, it also conditioned the subsequent interpretation of the episode in artefacts. The article makes an attempt to find the probable sources of Tolstoy's version of the events and reconstruct Kutuzov's meeting with Wolzogen. With reference to a historical document, the author restores the good name of the German officer serving in the Russian Army. The author first publishes the account of the events made in 1816 and stored in the collection of the Historical Service of the French Ministry of Defense.

Keywords: Battle of Borodino; M. I. Kutuzov; L. Wolzogen; L. N. Tolstoy.

Л. Н. Толстой в романе «Война и мир» описал сцену, где в ходе Бородинского сражения в ставку М. И. Кутузова прибывает флигель-адъютант Л. Вольцоген, который пытается уверить главнокомандующего в том, что сражение проиграно. Кутузов отвергает его донесение и заявляет, что неприятель разбит и русская армия перейдет завтра в наступле- 
ние. Под пером писателя встреча получила ироническую окраску, эпизод демонстрировал различное человеческое и национальное отношение к войне. В образе Кутузова воплотились проницательность и мудрость, спокойствие и вера в русскую армию. Людвиг Вольцоген, офицер немецкого происхождения, отличается педантичной расчетливостью, неверием в возможности русских одержать победу. Помимо того, что такое описание вызывало соответственное отношение читателей Толстого, оно предопределило дальнейшую интерпретацию эпизода в артефактах. В статье выявляются вероятные источники версии Толстого и с возможной исторической достоверностью реконструируется картина встречи Кутузова и Вольцогена. На основе исторического документа автор восстанавливает доброе имя мужественного немецкого офицера на русской службе. Впервые публикуется запись обстоятельств этого эпизода, сделанная в 1816 г. и хранящаяся в фондах Исторической службы Министерства обороны Франции. Документ приводится на оригинале (французский язык) и в переводе на русский.

Ключевые слова: Бородинское сражение, М. И. Кутузов, Л. Вольцоген, Л. Н. Толстой.

В главе XXXV второй части третьего тома «Войны и мира» Лев Толстой описал сцену приезда флигель-адъютанта Людвига фон Вольцогена с донесением от главнокомандующего 1-й Западной армией М. Б. Барклая де Толли о ходе дел в центре и на левом фланге.

Благоразумный Барклай де Толли, видя толпы отбегающих раненых и расстроенные зады армии, взвесив все обстоятельства дела, решил, что сражение было проиграно, и с этим известием прислал к главнокомандующему своего любимца.

Кутузов с трудом жевал жареную курицу и сузившимися, повеселевшими глазами взглянул на Вольцогена.

Вольцоген, небрежно разминая ноги, с полупрезрительной улыбкой на губах, подошел к Кутузову, слегка дотронувшись до козырька рукою. $<\ldots>$ «Der alte Herr (как называли Кутузова в своем кругу немцы) macht sieht ganz bequem», - подумал Вольцоген и, строго взглянув на тарелки, стоявшие перед Кутузовым, начал докладывать старому господину положение дел на левом фланге так, как приказал ему Барклай и как он сам его видел и понял.

- Все пункты нашей позиции в руках неприятеля и отбить нечем, потому что войск нет; они бегут, и нет возможности остановить их, - докладывал он.

Кутузов, остановившись жевать, удивленно, как будто не понимая того, что ему говорили, уставился на Вольцогена. Вольцоген, заметив волнение des alten Herrn, с улыбкой сказал:

- Я не считал себя вправе скрыть от вашей светлости того, что я видел... Войска в полном расстройстве... 
- Вы видели? Вы видели?.. - нахмурившись, закричал Кутузов, быстро вставая и наступая на Вольцогена. - Как вы... как вы смеете!.. - делая угрожающие жесты трясущимися руками и захлебываясь, закричал он. - Как смеете вы, милостивый государь, говорить это мне. Вы ничего не знаете. Передайте от меня генералу Барклаю, что его сведения неверны и что настоящий ход сражения известен мне, главнокомандующему, лучше, чем ему.

Вольцоген хотел возразить что-то, но Кутузов перебил его.

- Неприятель отбит на левом и поражен на правом фланге. Ежели вы плохо видели, милостивый государь, то не позволяйте себе говорить того, чего вы не знаете. Извольте ехать к генералу Барклаю и передать ему назавтра мое непременное намерение атаковать неприятеля, - строго сказал Кутузов. Все молчали, и слышно было одно тяжелое дыхание запыхавшегося старого генерала. - Отбиты везде, за что я благодарю Бога и наше храброе войско. Неприятель побежден, и завтра погоним его из священной земли русской, - сказал Кутузов, крестясь; и вдруг всхлипнул от наступивших слез. Вольцоген, пожав плечами и скривив губы, молча отошел к стороне... [Толстой, с. 249-250] ${ }^{1}$.

На какие свидетельства опирался Л. Н. Толстой? Впервые описание этой сцены было опубликовано в 1851 г. в воспоминаниях самого Вольцогена. В день Бородинского сражения он состоял в должности дежурного штаб-офицера при главнокомандующем 1-й Западной армии М. Б. Барклае де Толли. В воспоминаниях он написал, что после взятия французами Курганной высоты (в ходе боя под ним была убита лошадь, и он, контуженный, таща на себе седло, с трудом вышел из гущи боя) [Wolzogen, S. 142-143]². Барклай де Толли отправил его к главнокомандующему соединенными армиями М. И. Кутузову доложить о критическом положении русских войск и испросить у него распоряжений, добавив при этом, что важно получить эти распоряжения в письменном виде, «поскольку с Кутузовым следует быть осторожным» [Wolzogen, S. 145].

Вольцоген нашел Кутузова возле главной дороги на Москву, «в получасе езды позади армии». Недавно вырвавшийся из ожесточенного боя, контуженный Вольцоген увидел свиту главнокомандующего, состоявшую «почти исключительно из молодых богатых и знатных русских офицеров, которые упивались всевозможными удовольствиями, не принимая никакого участия в ужасных и серьезных событиях дня. Среди них был полковник Толь ${ }^{3}$ который был занят поеданием каплуна». Вольцоген сообщил о позиции, которую занимала русская

\footnotetext{
${ }^{1}$ Эта сцена появилась в знаменитой экранизации «Войны и мира», осуществленной в 1960-е гг. С. Ф. Бондарчуком. В роли Кутузова снялся Б. Захава, в роли Л. Вольцогена - Янис Грантиньш. Бондарчук заметно «состарил» Вольцогена, которому в 1812 г. было 39 лет. Кроме того, в тексте романа Вольцоген дотрагивается «до козырька рукою», то есть должен быть в фуражке, тогда как на экране на нем двуугольная шляпа.

2 Здесь и далее перевод цитат и документов - автора статьи.

${ }^{3}$ К. Ф. Толь (1777-1842), в 1812 г. полковник, и. д. генерала-квартирмейстера действующих армий.
} 
армия и охарактеризовал тяжесть ее состояния: «все важные пункты были потеряны, а полки истощены и пришли в расстройство». В ответ на это

Кутузов закричал: «С какой гнусной (hundsföttischen) маркитанткой вы так напились, что являетесь ко мне с таким абсурдным (abgeschmackten) рапортом? Как идет сражение, я все-таки лучше знаю! Атаки французов везде победоносно отбиты, и завтра я сам встану во главе армии, чтобы изгнать врага без остатка со святой русской земли!» При этом он с торжествующим вызовом оглядел свою свиту, которая ответила ему восторженными аплодисментами [Wolzogen, S. 146].

Вольцоген был неприятно поражен приемом, оказанным ему главнокомандующим и его свитой, тем более что он «только что видел своими глазами и в пекле (Gewühl) битвы», в то время как «Кутузов провел весь день в тылу армии среди бутылок шампанского и деликатесов» [Wolzogen, S. 145].

Через пять лет после выхода мемуаров Вольцогена биограф К. Ф. Толя Т. Бернгарди упомянул о его приезде в ставку Кутузова, опуская детали произошедшего разговора, зато подчеркивая ключевую роль Толя, составлявшего приказы, которые главнокомандующий только подписывал. И уж конечно он не счел возможным упоминать поедаемого Толем каплуна [Bernhardi, S. 107-108].

Через несколько лет описание сцены появляется на страницах исторического труда М. И. Богдановича, который был знаком с мемуарами Вольцогена и с сочинением Бернгарди и считал, «что Вольцоген, объясняя князю Кутузову состояние нашей армии, увлекся пылкостью воображения и донес главнокомандующему совершенно противное тому, что поручено было ему Барклаем» [Богданович, с. 219-220, 547-548, примеч. 23)]. Богданович постарался обойти молчанием многие детали сцены и сгладить резкость речей ее участников, хотя справедливо связал приезд Вольцогена с решением главнокомандующего возобновить сражение на следующий день ${ }^{4}$. Барклаю де Толли и Д. С. Дохтурову, который после ранения П. И. Багратиона принял командование 2-й Западной армией, Кутузов отправил записки аналогичного содержания: «Я из всех движений неприятельских вижу, что он не менее нас ослабел в сие сражение, и потому, завязавши уже дело с ним, решился я сегодняшнюю ночь устроить все войско в порядок, снабдить артиллерию новыми зарядами и завтра возобновить сражение с неприятелем. Ибо всякое отступление при теперешнем беспорядке повлечет за собою потерю всей артиллерии» [Бородино: Документы, письма, воспоминания, с. 96-97; Бородино. Документальная хроника, с. 111].

${ }^{4}$ Богданович убедительно ссылался на воспоминания Н. Н. Раевского, начальника 7-го пехотного корпуса, который прибыл к Кутузову сразу после разговора последнего с Вольцогеном. См.: [Бородино: Документы, письма, воспоминания, с. 96-97; Бородино. Документальная хроника, с. 382]. 
Лев Толстой, собирая материал для описания Бородинского сражения, познакомился с достаточно большим кругом источников и исторических сочинений. В его библиотеке сохранился труд Бернгарди, причем третий и четвертый тома были не разрезаны, в то время как второй том он определенно читал [Список книг, с. 143]. Столь же совершенно определенно Толстой читал Богдановича, впрочем, отзывался о нем достаточно негативно, предпочитая сочинение А. И. Михайловского-Данилевского. Полагаем, что и мемуары Вольцогена тоже были знакомы писателю, судя по появлению в сцене приезда Вольцогена «жареной курицы», которую, правда, ест не Толь, а сам главнокомандующий.

Стоит ли удивляться, что гениальный роман Толстого определил в дальнейшем трактовку отечественными авторами этого эпизода в толстовском духе? Именно так преподнесли его исторические романисты М. Г. Брагин и О. Н. Михайлов [Брагин; Михайлов], кинематографист С. Ф. Бондарчук, автор рэп-рок-оперы «Война и мир» Наталья Тугаринова, известный военный историк А. А. Свечин [Свечин, с. 171] ... Даже Н. А. Троицкий, историк, который не был склонен идеализировать образ Кутузова, все же не решился поставить под сомнение хрестоматийную версию события [Троицкий, 1988, с. 173, 334, примеч. 70; Троицкий, 2002, с. 191-192] $]^{5}$.

Между тем личность Вольцогена заслуживает того, чтобы прислушаться к его словам. Юстус Адольф Филипп Вильгельм Людвиг фон Вольцоген, родившийся в 1774 г. в Майнингене, герцогство Саксен-Хильдбургхаузен, в семье дипломата, рано лишился обоих родителей. Воспитанный в штутгартской военной школе, он после ее окончания служил в армиях Вюртемберга и Пруссии. Находясь на прусской службе, сблизился с Г. Шарнгорстом $^{6}$ и принимал участие в обсуждении различных военных теоретических и практических проблем. В 1801-1804 гг. обучал молодого герцога Евгения Вюртембергского, благодаря которому в 1807 г.

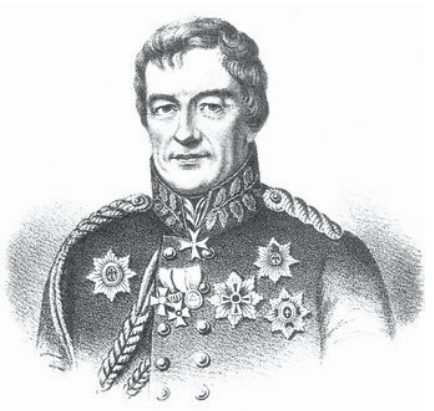
был принят на русскую службу майором квартирмейстерской части. К этому времени Вольцоген имел опыт участия в боевых действиях в составе вюртембергского контингента в 1805 г. в войне против Австрии. К началу войны 1812 г. он был уже хорошо известен как автор ряда работ в сфере военного дела, был близок к генералу К. Л. Фулю.

${ }^{5}$ В отличие от отечественной традиции, англоязычные авторы предпочитают в воспроизведении рассматриваемого эпизода ориентироваться на версию самого Вольцогена. См., например: [Zamoysky, p. 285; Mikaberidze, p. 198-199].

${ }^{6}$ Г. И. Д. Шарнгорст (1755-1813), выдающийся прусский военный теоретик, военный организатор и военачальник. С 1802 г. преподавал в Берлинской военной академии. В дальнейшем военный министр, начальник прусского генерального штаба, генерал-лейтенант. 
Император Александр I, который лично знал и ценил Вольцогена, назначил его флигель-адъютантом и произвел в подполковники, а затем в полковники. С июля 1812 г. Вольцоген исполнял должность квартирмейстера при штабе 1-й Западной армии, а затем дежурного штабофицера при ее главнокомандующем Барклае де Толли. Несмотря на близость к Фулю, Вольцоген выступил против размещения 1-й Западной армии в Дрисском лагере. За отличие в Бородинском сражении Вольцоген получил орден Св. Анны 2-й степени с алмазами, за Тарутино - золотую шпагу «За храбрость». Он был участником сражений при Бауцене, Кульме, Лейпциге, Ла-Ротьере и боев в Нидерландах. В октябре 1813 г. произведен в генерал-майоры. В мае 1815 г. он переходит на прусскую службу и уходит в отставку в 1836 г. с чином генерала от инфантерии [Wolzogen; Priesdorff, S. 180-184; Горшман, с. 344-345; Попов, с. 360-361].

В фондах Исторической службы Министерства обороны Франции сохранилось документальное свидетельство о том, что история встречи Вольцогена с Кутузовым и его свитой на Бородинском поле была известна задолго до публикации воспоминаний немецкого генерала. Документ составлен на французском языке, написан черными чернилами на обеих сторонах одного листа серо-голубой бумаги, аналогичной образцам, которые использовались в первой половине XIX в. Почерк, по-видимому, писарский. Ниже заголовка другой рукой чернилами на французском языке сделана плохо различимая надпись, которую можно прочитать так: «это то,что было услышано генералом Орловым ${ }^{7}$ у генерала Жомини ${ }^{8}$ в марте (?) 1816». Еще ниже вторая плохо различимая надпись на французском языке карандашом, сделанная, как полагаем, в XIX в. сотрудником архива: «то, что добавлено, сделано рукой генерала Коха (Koch)» ${ }^{9}$. С левой стороны листа имеется помета чернилами «1812». Ниже карандашом (полагаем, что архивистом) сделана еще одна надпись: «Битва при Москвереке (Moskowa) 7 сентября 1812».

Приведем текст документа полностью, сохраняя по возможности орфографию и пунктуацию оригинала, и ниже его перевод.

\section{Anecdote sur la Campagne de Russie}

Tous général Russe qui a éprouvé une de faite cherche à en atténuer les effets dans l'opinion en cherchons à l'égarer dans les premiers momens par

${ }^{7}$ Полагаем, что имеется в виду М. Ф. Орлов (1788-1842), участник войны 1812 г., произведенный в апреле 1814 г. в генерал-майоры, в 1815-1820 гг. начальник штаба 7-го, затем 4-го пехотного корпуса.

${ }^{8}$ А. А. Жомини (1779-1869), известный военный теоретик, состоявший в 18131817 гг. на русской службе. Находясь в России, начал работу над составлением труда об Отечественной войне 1812 г., однако не довел ее до конца и в 1817 г. покинул Россию.

${ }^{9}$ К.И. Г. Кох (Косh) (1769-1826), вюртембергский генерал-лейтенант (1813), в 1812 г. командир 2-й бригады 5-й пехотной дивизии Великой армии. Ранен под Смоленском. В начале 1813 г. командовал 2-й пехотной бригадой, затем произведен в генерал-лейтенанты. В 1814 г. командовал пехотной дивизией 7-го германского корпуса. 
des rapports mensonger, s'il ne réussir par, il est disgracié. La première impression donnée le people reviens difficilemens sur la véracite de la première nouvelle quil areçue es lors que la vérite arrive on n'y ajoute aucune foi. Kutusow ne l'ignnorais pas. Lors que la bataille de la Moskowa fut engage généralement il prévoir son issue es agir en consequence. Il choisir le moment ou il $<$ неразборчиво > de repousser une attaque des français pour annomcer à son nombreux Etat major que la bataille étais gagnée. «Jе <неразборчиво> mon armée se sera repose, je poursuivrai l'ennemi es recueillerais le fruit de notre victoire. Allons Messieurs suivez moi.

Arrivé à une lieue du champ de bataille il fis apporter tout ce qu'il fallais pour écrire et fit son rapport. Le Peince d'Oldenbourg étais prés de lui, il l'engagea à se servir de son papier es de son encre pour donner de ses nouvelles à la princesse. Le Prince fut en quelque sorte dans l'obligation d'écrire dans le même sens que le general, sa letter commençais ainsi: Enfin, ma chere amie nous venons de remporter la victoire la plus complete, l'ennemi est en pleine déroute etc, etc. Les officiers de l'Etat major en firent autant. Le ruse general prévoyan bien que ces letters formeraient une premiére opinion et que grands personages aux quelles elles étaiens adressées pour la plupart, la soutiendraient pour ne pas avouer avoir ete trompés les premiers. Au moment où le courier alloit parter arrive, ventre à terre M. de Wolshogen, officier allemande au service de Russie. "Où est sécriet-il, M. le Maréchal? Je dois parler à M. le Maréchal, qu'est ce?, quy a-t-il! - Monsieur le M-al, dit l'officier, "Le g-al Barclay de Tolly me charge de vous prévenir que l'ennemi a fait les plus grands efforts, que son aile gauche a enfin reuse dans son attaques, qu'elle s'essemparée de la redoute principale, le g-al demande des orders et des renforte; il crains d'étre accablé. - Mon ami vous êtes dans l'erreur, répond le Maréchal, vous êtes parti du champ de bataille avant moi. Tout est réparé, jai donné les orders necessaries. Lofficier vens en vain dissuader le Maréchal ou sens qu'il ne <неразборчиво> parvenir - Taisez-vous vous dis je vous vous tromper; Courrier partez donc, et dés votre entrée à Petersbourg nemanquez pas de crier victoire - Le courier pique des deux et disparais. Lofficier parviens alors à se faire entendre. Je vous assure M. le Maréchal que je suis pas après vous; Mon cheval est bon, voyez dans quell état il est. Eh, bien! Voyons, qu' avez vous à me dire. Lofficier surprés dit a voix basse: Nous sommes batteur; l’armée se retire... Le Maréchal élevaus la voix: Pourquoi donc Barclay quitte t-il sa position? Je lui avois ordonné de rester sur le champ de bataille, de faire reposer l'armée, afin de mieux poursuivre demain. Je retourne lui réitérer, moi meme, mes intentions [Service historique de la Défance. C2 130].

\section{(Эпизод из истории Русской кампании}

Хваленый русский генерал, терпящий поражение, уже с первых моментов ищет возможность смягчить эффект, который будет произведен в общественном мнении, и делает это с помощью лживых рапортов, если и не повествующих об успехе, то по крайней мере оправдывающих его. Первое впечатление заставляет человека с трудом принять то, что первая новость, которую он получил и которая, как он считал, правдива, в действительности не внушает веры. Кутузов понимал это. Когда сра- 
жение при Москве-реке началось обычным порядком, он предусмотрел свои последующие действия. Он выбрал момент, когда увидел, что атака французов была отбита и воспользовался этим, дабы объявить своему многочисленному штабу, что сражение выиграно. «Я <нрзб.> моя армия устояла, я преследую врага и собираюсь пожать плоды нашей победы. Идемте, господа, следуйте за мной».

Приблизившись на расстояние в одно лье ${ }^{10}$ от поля битвы, он привез все то, что было необходимо для письма, и составил рапорт. Князь Ольденбургский ${ }^{11}$ оказался рядом, и он вручил ему бумагу, с тем чтобы тот сообщил новость княгине ${ }^{12}$. Ему было вменено своего рода в обязанность написать в том самом духе, как написал генерал, а письмо начиналось так: «Наконец, мой дорогой друг, мы одержали совершенную викторию, враг полностью разгромлен, и т. д. и т. д.». Офицеры штаба должны были сделать то же самое. Русский генерал верно предусмотрел, что эти письма определят первое впечатление, и что важные персоны, которым они, большей частью, будут адресованы, окажут впоследствии поддержку, так как не захотят признать обман и то, что были первоначально введены в заблуждение. В тот момент, когда курьер уже собирался отъехать, прибыл и сошел с лошади господин де Вольцоген, немецкий офицер на русской службе. «Где, - вскрикнул он, - господин маршал?' Я должен говорить с господином маршалом, где он?» И вот что он сказал: «Господин маршал, - сказал офицер, - генерал Барклай де Толли поручил мне предупредить вас, что враг предпринял самые серьезные усилия против вашего левого фланга и наконец добился в своих атаках успеха, и в ходе их он завладел главным редутом. Генерал требует распоряжений и просит подкреплений; он опасается быть сломленным». «Мой друг, вы ошибаетесь, - отвечал маршал, - вы покинули поле боя еще до меня. Все уже отбито, я отдал необходимые приказы». Офицер напрасно разубеждал маршала, он ничего не добился. «Не говорите этого, не вводите меня в заблуждение; курьер отправлен, и при вашем приезде в Петербург не будет недостатка в победных криках». [Курьер был дважды проткнут

${ }^{10}$ Французская сухопутная мера длины, равная примерно 4,5 км. На таком расстоянии от Курганной высоты могла быть только д. Татариново. Однако, судя по всему (это подтверждается и мемуарами Вольцогена), речь идет о районе д. Горки, которая расположена от Курганной высоты примерно в 2 км. Вопрос о месте расположения командного пункта М. И. Кутузова в день Бородинского сражения остается дискуссионным до сих пор [Троицкий, 1988, с. 165; Горбунов; Ивченко; и др.]. Очевидно, что во время сражения Кутузов вместе со штабом по крайней мере однажды выезжал от Горок ближе к передовой линии, в район за 6-м пехотным корпусом.

${ }^{11}$ Павел Фридрих Август Ольденбургский (1783-1853), герцог, генерал-лейтенант (1811), двоюродный брат императора Александра I. В 1812 г. был прикомандирован к действующей армии. Накануне Бородинской битвы убеждал Кутузова не оставлять Москву [Степанов, с. 5].

12 Имеется в виду сестра Александра I вел. кн. Екатерина Павловна, вышедшая замуж за брата П. Ф. А. Ольденбургского принца Георгия Ольденбургского, который находился на момент Бородинского сражения в Твери, а сама вел. кн. Екатерина Павловна - в Ярославле.

${ }_{13}$ М. И. Кутузов был удостоен чина генерал-фельдмаршала только 30 августа (ст. ст.) 1812 г. за сражение при Бородино. На момент сражения он был в чине генерала от инфантерии. 
пикой и погиб.] Офицер все же пытался добиться, чтобы его услышали. «Я вас уверяю, господин маршал, что я был после вас. Моя лошадь хороша, посмотрите, в каком она состоянии». «Ну что же! Посмотрим, что вы мне хотите сказать?» Офицер удивленно сказал басом: «Мы разбиты; армия отступает...» Маршал повысил голос: «Почему Барклай покинул позиции? Я ему приказываю оставаться на поле боя, дать армии отдых, дабы успешнее преследовать [неприятеля] завтра. Я сам вновь повторю ему свои намерения») [Service historique de la Défance. C2 130].

Процитированный документ вряд ли может кардинально уточнить представления о характере встречи Вольцогена и Кутузова 26 августа (7 сентября) 1812 г., однако он заставляет по-новому взглянуть на весь комплекс источников, повествующих об этой встрече. Под пером Толстого встреча превратилась в символическое столкновение проницательности и мудрости, воплощенных в образе Кутузова, и достойной презрения доктринерской расчетливости - в лице немца Вольцогена. Историческая справедливость подсказывает, что, говоря о полководческих талантах и степени дальновидности русского главнокомандующего, проявленных им в день Бородинского сражения, вряд ли стоит принижать личность Вольцогена, достойного офицера, который, выйдя контуженным из пекла боя, увидел на командном пункте Кутузова стайку праздной золотой молодежи и полковника Толя, поедающего жирного каплуна.

\section{Список литературы}

Богданович М. И. История Отечественной войны 1812 г. по достоверным источникам. СПб. : Тип. ТД С. Струговщикова, Г. Похитонова, Н. Водова и Ко, 1859. Т. 2. VII, $652 \mathrm{c}$.

Бородино. Документальная хроника. М. : РОССПЭН, 2004. 384 с.

Бородино : Документы, письма, воспоминания. М. : Советская Россия, 1962. 412 с.

Брагин М. Г. Кутузов. М. : Молодая гвардия, 1975. 224 с.

Горбунов А. В. Место расположения Главной квартиры М. И. Кутузова на Бородинском поле // Отечественная война 1812 года. Источники. Памятники. Проблемы. Бородино : Гос. Бородинский военно-ист. музей-заповедник, 1997. С. 3-9.

Горшман А. Вольцоген Л. Ю. А. Ф. // Российский архив. Т. 7. М. : Студия «Тритэ» Никиты Михалкова : Российский архив, 1996. С. 344-345.

Ивченко Л. Л. М. И. Кутузов в Бородинском сражении // Отечественная война 1812 года. Источники. Памятники. Проблемы. Бородино : Гос. Бородинский военноист. музей-заповедник, 1997. С. 10-27.

Михайлов О. Н. Генерал Ермолов. М. : Воениздат, 1983. 413 с.

Попов А. И. Вольцоген // Отечественная война 1812 г. и освободительный поход русской армии 1813-1814 гг. М. : РОССПЭН, 2012. Т. 1. С. 360-361.

Свечин А. А. Клаузевиц. М. : Журнально-газетное объединение, 1935. 288 с.

Список книг, которыми пользовался Л. Н. Толстой во время писания «Воины и мира» / сост. Э. Е. Зайденшнур // Толстой Л. Н. Полн. собр. соч. : в 90 т. Т. 16. М. : Художественная литература, 1955. С.141-145.

Степанов Ю. Г. Павел Фридрих Август Ольденбургский // Отечественная война 1812 г. и освободительный поход русской армии 1813-1814 гг. М. : РОССПЭН, 2012. T. 3. C. 5 .

Толстой Л. Н. Война и мир // Толстой Л. Н. Полн. собр. соч. : в 90 т. Т. 11. М. : Художественная литература, 1940. 329 с. 
Троиикий Н. А. 1812. Великий год России. М. : Мысль, 1988. 348 с. $367 \mathrm{c}$.

Троищкий Н. А. Фельдмаршал Кутузов: мифы и факты. М. : Центрполиграф, 2002.

Bernhardi T. von. Denkwürdigkeiten des Kaiserl.-russ. Generals von der Infanterie Karl Fridrich Grafen von Toll... Bd. 2. Leipzig: Otto Wigand, 1856. VI, 482 S.

Mikaberidze A. The Battle of Borodino. Barnsley : Pen and Sword Military, 2007. XXIV, $276 \mathrm{p}$.

Priesdorff K. von. Soldatisches Führertum. Bd. 4. Hamburg : Hanseatische Verlagsanstalt, 1937. $512 \mathrm{~S}$.

Service historique de la Défance. C2 130.

Wolzogen L. von. Memoiren des Königlich Preussischen Generals der Infanterie Ludwig Freiherr von Wolzogen. Leipzig : Otto Wigand, 1851. 311 S., CXXXVI.

Zamoysky A. 1812. Napoleon's Fatal March on Moscow. London : Harper Perennial, 2004. XXVI, 644 p.

\section{References}

Bernhardi, T. von. (1856). Denkwürdigkeiten des Kaiserl.-russ. Generals von der Infanterie Karl Fridrich Grafen von Toll... (Bd. 2).VI, 482 S. Leipzig, Otto Wigand.

Bogdanovich, M. I. (1859). Istoriya Otechestvennoj vojny' 1812 g. po dostoverny'm istochnikam [The History of the Patriotic War of 1812 Based on Reliable Sources]. (Vol. 2). VII, 652 p. Saint Petersburg, Tipografiya TD S. Strugovshhikova, G. Pohitonova, N. Vodova i Ko.

Borodino. Dokumental'naya hronika [A Documentary Chronicle]. (2004). 384 p. Moscow, ROSSPEN.

Borodino: Dokumenty', pis'ma, vospominaniya [Documents, Letters, Memoirs]. (1962). 412 p. Moscow, Sovetskaya Rossiya.

Bragin, M. G. (1975). Kutuzov [Kutuzov]. 224 p. Moscow, Molodaya gvardiya.

Gorbunov, A. V. (1997). Mesto raspolozheniya Glavnoj kvartiry' M. I. Kutuzova na Borodinskom pole [The Location of M.I. Kutuzov's Headquarters in Borodino Field]. In Otechestvennaya vojna 1812 goda. Istochniki. Pamyatniki. Problemy' (pp. 3-9). Borodino, Gosudarstvenny'j Borodinskij voenno-istoricheskij muzej-zapovednik.

Gorshman, A. (1996). Vol'czogen L. Yu. A. F. [Wolzogen L. J.]. In Rossijskij arhiv. (Vol. 7, pp. 344-345). Moscow, Studiya «Trite'» Nikity' Mihalkova, Rossijskij arhiv.

Ivchenko, L. L. (1997). M. I. Kutuzov v Borodinskom srazhenii [M. I. Kutuzov in the Battle of Borodino]. In Otechestvennaya vojna 1812 goda. Istochniki. Pamyatniki. Problemy' (pp. 10-27). Borodino, Gosudarstvenny'j Borodinskij voenno-istoricheskij muzejzapovednik. nizdat.

Mihajlov, O. N. (1983). General Ermolov [General Yermolov]. 413 p. Moscow, Voe-

Mikaberidze, A. (2007). The Battle of Borodino. XXIV, 276 p. Barnsley, Pen and Sword Military.

Popov, A. I. (2012). Vol'czogen [Wolzogen]. In Otechestvennaya vojna $1812 \mathrm{~g}$. $i$ osvoboditel'ny'j pohod russkoj armii 1813-1814 gg. (Vol. 1). 713 p. Moscow, ROSSPEN.

Priesdorff, K. von. (1937). Soldatisches Führertum. Bd. 4. 512 S. Hamburg, Hanseatische Verlagsanstalt.

Service historique de la Défance. C2 130.

Stepanov, Yu. G. (2012). Pavel Fridrih Avgust Ol'denburgskij [Paul Friedrich August, Grand Duke of Oldenburg]. In Otechestvennaya vojna $1812 \mathrm{~g}$. i osvoboditel'ny'j pohod russkoj armii 1813-1814 gg. (Vol. 3). 760 p. Moscow, ROSSPEN.

Svechin, A. A. (1935). Klauzevicz [Clausewitz]. 288 p. Moscow, Zhurnal'no-gazetnoe $\mathrm{ob}^{\prime \prime}$ edinenie.

Tolstoj, L. N. (1940). Vojna i mir [War and Peace]. In Tolstoj, L. N. Polnoe sobranie sochinenij (in 90 vols.). (Vol. 11). 329 p. Moscow, Hudozhestvennaya literatura.

Troiczkij, N. A. (1988). 1812. Velikij god Rossii [The Great Year of Russia]. 348 p. Moscow, My'sl'.

Troiczkij, N. A. (2002). Fel'dmarshal Kutuzov: mify' i fakty' [Field Marshal Kutuzov: Myths and Facts]. 367 p. Moscow, Centrpoligraf. 
Wolzogen, L. von. (1851). Memoiren des Königlich Preussischen Generals der Infanterie Ludwig Freiherr von Wolzogen. CXXXVI, 311 S. Leipzig, Otto Wigand.

Zajdenshnur, E'. E. (Comp.) (1955). Spisok knig, kotory'mi pol'zovalsya L. N. Tolstoj vo vremya pisaniya "Voiny' i mira» [A List of Books Used by L. Tolstoy while Writing War and Peace]. In Tolstoj, L. N. Polnoe sobranie sochinenij (in 90 vols.). (Vol. 16, pp. 141-145). Moscow, Hudozhestvennaya literatura.

Zamoysky, A. (2004). 1812. Napoleon's Fatal March on Moscow. XXVI, 644 p. London, Harper Perennial.

The article was submitted on 08.05.2015

\author{
Владимир Николаевич Земцов, \\ профессор, \\ Уральский государственный \\ педагогический университет, \\ Екатеринбург, Россия \\ vladimirzemtsov@yandex.ru
}

\author{
Vladimir Zemtsov, \\ Professor, \\ Ural State Pedagogical University, \\ Yekaterinburg, Russia \\ vladimirzemtsov@yandex.ru
}

